\title{
Study publication date should not dictate suitability of methodological and reporting quality assessment
}

\section{Rafael Leite Pacheco ${ }^{1}$ (1) Luis Eduardo Santos Fontes ${ }^{2}$ (1) Enderson Miranda ${ }^{3}$ (1) Ana Luiza Cabrera Martimbianco ${ }^{4}$ (1) Rachel Riera ${ }^{5}$ (1)}

\author{
${ }^{1}$ Corresponding author. Universidade Federal de São Paulo (São Paulo), Centro Universitário São Camilo (São Paulo). São Paulo, Brazil. \\ rleitepacheco@hotmail.com \\ ${ }^{2}$ Faculdade de Medicina de Petrópolis (Petrópolis). Rio de Janeiro, Brasil. luis.fontes@ceo2.com.br \\ ${ }^{3}$ University of Oxford (Oxford). United Kingdom. enderson.miranda@kellogg.ox.ac.uk \\ ${ }^{4}$ Centro Universitários São Camilo (Sâo Paulo), Universidade Metropolitana de Santos (Santos). São Paulo, Brazil. analuizacabrera@hotmail.com \\ ${ }^{5}$ Núcleo de Avaliação de Tecnologias em Saúde, Hospital Sírio-Libanês (São Paulo), Universidade Federal de São Paulo (São Paulo).
} São Paulo, Brazil. rachelriera@hotmail.com

KEYWORDS: Methodological studies. Reporting guidelines. Critical appraisal. Systematic reviews.

\section{Main text}

"Research-on-research" studies, also known as methodological studies, have the main purpose of evaluating certain methodological aspects of published research, which includes methodological and reporting quality characteristics from previous studies $^{1-3}$. Research-on-research studies have an important implication on helping the conception, design, and conduction of future studies 4,5 . Therefore, assessing previous research is essential in avoiding unnecessary duplication and waste ${ }^{6,7}$.

The critical appraisal process of healthcare literature is typically based on three core criteria: methodological quality assessment, completeness, and transparency of reporting.
Tools and guidelines have been developed over the years in the attempt to standardize the methodological quality assessment. The AMSTAR-2 (A Measurement Tool to Assess Systematic Reviews) ${ }^{8}$ and the QUADAS-2 (Quality Assessment of Diagnostic Accuracy Studies) ${ }^{9}$ are two of the most used instruments for assessing the methodological quality of systematic reviews and diagnostic accuracy studies worldwide.

Quality assessment related to the transparency of reporting and completeness of publications is usually performed by checking its adherence to a pre-determined checklist designed to systematically guide reporting ${ }^{10,11}$. The EQUATORnetwork database (http://www.equator-network. org/) has published 422 reporting guidelines to date with 83 additional reporting guidelines under development. This reflects the increased popularity of such guidelines, whose dissemination and adherence are also encouraged by the International Committee of Medical Journal Editors ${ }^{12}$. 
Evaluators often question the validity of utilizing tools during the critical appraisal process if such tools were created after the study was conducted and/or published. The common argument is that it would be unfair to assess the adherence to a recommendation that did not exist at that time. Based on this argument, some authors have restricted the evaluation to only include studies published after the tool has become available ${ }^{13-15}$. Furthermore, certain critical appraisal studies have published in their discussion sessions that the utilization of a quality assessment tool in studies published before the tool's development should be considered as a limitation of the studies ${ }^{16-18}$.

We do not agree with this argument as we believe that the basic principles of well-conducted and properly reported studies should be known and fulfilled before the development of any appraisal tool. Furthermore, transparency and reproducibility have always been a key best practice within the scientific process. Thus, the recommendation that studies should be conducted with a minimum methodological rigor should be followed regardless of the existence of a valid tool to systematically evaluate their quality. It is reasonable to assume that risk of bias and uncertainty in the results derived from a poor quality study would occur regardless of the existence of a specific tool when the study was conducted and/or published. The results from studies that were conducted prior to the existence of a valid methodological evaluation tool should not be shielded from biases associated to its low internal validity.

The proper evaluation of healthcare literature published prior to the existence of a relevant quality assessment tool creates an important opportunity to benchmark study quality over time by comparing recent reports with previous ones. This is critical to confirm if the quality assessment tool was actually able to promote an enhancement in the methodological and/or reporting process ${ }^{10,19,20}$.

In conclusion, all published studies must be appraised for its methodological and reporting quality, regardless of their publication date. Removing appraisal restrictions based on date thresholds would allow us to learn from our past mistakes, which can be a great way to avoid waste in research and significantly improve the overall quality of future studies.

\section{Author contributions}

This paper was produced, reviewed, and approved by all the authors collectively.

\section{Competing interests}

No financial, legal or political competing interests with third parties (government, commercial, private foundation, etc.) were disclosed for any aspect of the submitted work (including but not limited to grants, data monitoring board, study design, manuscript preparation, statistical analysis, etc.).

\section{References}

1. Puljak L. Methodological studies evaluating evidence are not systematic reviews. J Clin Epidemiol. 2019;110:98-99. doi: 10.1016/j.jclinepi.2019.02.002

2. Puljak L. Research-on-research studies or methodological studies are primary research. J Clin Epidemiol. 2019;112:95. doi: 10.1016/j.jclinepi.2019.04.013

3. Puljak L. Reporting checklist for methodological, that is, research on research studies is urgently needed. J Clin Epidemiol. 2019;112:93. doi: 10.1016/j.jclinepi.2019.04.016

4. Puljak L. Methodological research: open questions, the need for 'research on research' and its implications for evidence-based health care and reducing research waste. Int J Evid Based Healthc. 2019;17(3):145-146. doi: 10.1097/XEB.0000000000000201

5. Ioannidis JPA. Meta-research: Why research on research matters. PLoS Biol. 2018;16(3):e2005468. doi: 10.1371/journal. pbio. 2005468

6. Chalmers I, Glasziou P. Avoidable waste in the production and reporting of research evidence. Lancet. 2009;374:86-9. doi: 10.1016/S0140-6736(09)60329-9

7. Glasziou P, Altman DG, Bossuyt P, Boutron I, Clarke M, Julious $S$ et al. Reducing waste from incomplete or unusable reports of biomedical research. Lancet. 2014;383(9913):267-76. doi: 10.1016/ S0140-6736(13)62228-X

8. Shea BJ, Reeves BC, Wells G, Thuku M, Hamel C, Moran J et al. AMSTAR 2: a critical appraisal tool for systematic reviews that include randomised or non-randomised studies of healthcare interventions, or both. BMJ. 2017;358:j4008. doi: 10.1136/bmj.j4008

9. Whiting PF, Rutjes AW, Westwood ME, Mallett S, Deeks JJ, Reitsma JB et al. QUADAS-2: a revised tool for the quality assessment of diagnostic accuracy studies. Ann Intern Med. 2011;155(8):529-36. doi: 10.7326/0003-4819-155-8-201110180-00009 
10. Turner L, Shamseer L, Altman DG, Peters J, Kober T, Dias S et al. Consolidated standards of reporting trials (CONSORT) and the completeness of reporting of randomised controlled trials (RCTs) published in medical journals. Cochrane Database Syst Rev. 2012;11:MR000030. doi: 10.1002/14651858.MR000030.pub2

11. Puljak L. Reporting checklists are used as measurement tools for assessing quality, even though they have not been validated for such use. Trials. 2019;20(1):676. doi: 10.1186/s13063-019-3858-6

12. International Committee of Medical Journal Editors (ICMJE). Preparing for Submission, Reporting Guidelines. [Internet]. 2020. [acesso em 2020 feb. 28]. Disponível em: http://www.icmje.org/ recommendations/browse/manuscript-preparation

13. Farrokhyar F, Chu R, Whitlock R, Thabane L. A systematic review of the quality of publications reporting coronary artery bypass grafting trials. Can J Surg. 2007;50(4):266-77.

14. Huang YQ, Traore K, Ibrahim B, Sewitch MJ, Lily H, Nguyen LHP. Reporting quality of randomized controlled trials in otolaryngology: review of adherence to the CONSORT statement. J Otolaryngol Head Neck Surg. 2018;47(1):34. doi: 10.1186/s40463018-0277-8

15. Choi J, Jun JH, Kang BK, Kim KH, Lee MS. Endorsement for improving the quality of reports on randomized controlled trials of traditional medicine journals in Korea: a systematic review. Trials. 2014;15:429. doi: 10.1186/1745-6215-15-429
16. Li L, Xu C, Deng K, Zhou X, Liu Z, Busse JW et al. The reporting of safety among drug systematic reviews was poor before the implementation of the PRISMA harms checklist. J Clin Epidemiol. 2019;105:125-35. doi: 10.1016/j.jclinepi.2018.09.014

17. Stevanovic A, Schmitz S, Rossaint R, Schürholz T, Coburn M. CONSORT item reporting quality in the top ten ranked journals of critical care medicine in 2011: a retrospective analysis. PLoS One. 2015;10(5):e0128061. doi: 10.1371/journal.pone.0128061

18. Peters JP, Hooft L, Grolman W, Stegeman I. Assessment of the quality of reporting of randomised controlled trials in otorhinolaryngologic literature - adherence to the CONSORT statement. PLoS One. 2015;10(3):e0122328. doi: 10.1371/journal. pone. 0122328

19. Bigna JJ, Noubiap JJ, Asangbeh SL, Um LN, Sime PS, Temfack E et al. Abstracts reporting of HIV/AIDS randomized controlled trials in general medicine and infectious diseases journals: completeness to date and improvement in the quality since CONSORT extension for abstracts. BMC Med Res Methodol. 2016;16(1):138. doi: 10.1186/s12874-016-0243-y

20. Speich B, Mc Cord KA, Agarwal A, Gloy V, Gryaznov D, Moffa $G$ et al. Reporting quality of journal abstracts for surgical randomized controlled trials before and after the implementation of the CONSORT extension for abstracts. World J Surg. 2019:23712378. doi: 10.1007/s00268-019-05064-1 